\title{
'CONCEPTUAL TURN' IN RECENT PHILOSOPHY
}

ASH GOBAR

Transylvania University, U.S.A.

Contemporary philosophy has taken a 'conceptual turn' in recent years. This turn, however, unlike previous turns (i.e. the 'linguistic turn', the 'existential turn', etc.) is not the handiwork of any "school". Indeed, its practitioners are scattered wide and, in some instances, remain detached from each other. Yet, it would be accurate to say that the philosophers who have taken the 'conceptual turn' do share, in a nontrivial sense, a characteristic approach to philosophic problems.

In this article I will reconstruct the rationale and meaning of the 'conceptual turn'. Others who have taken the turn (as I have) may take exception to some point or other in my reconstruction; and some may present their own reconstructions. I do not wish to be the spokesman for a nonexisting "school". I only present the pattern as I see it.

Briefly, then, I will sketch: (1) the emerging paradigm of philosophy as a 'metascience' (versus 'metagrammar'), (2) the redefinition of the character of 'philosophic propositions' (versus nonphilosophic propositions); and (3) the ontological assumptions requisite for taking the 'conceptual turn'.

The materia philosophica, included in the "Sample Bibliography" appended to this article, are to be taken only as illustrative. They constitute but fragmentary evidence for the 'conceptual turn' in recent philosophy. Yet they display, explicity or implicitly, the character and the direction of the turn. 


\section{Para digm of Philosophy as 'Metascience' versus 'Metagrammar'}

"Die Philosophie ist keine der Naturwissenschaften (Das Wort 'Philosophie' muss etwas bedeuten, was über oder unter, aber nicht neben den Naturwissenschaften steht)", wrote Wittgenstein (Tractatus: prop. 4.111). No modern philosopher would disagree with this statement. But the moment anyone attempts to fix the function of philosophy precisely, whether "above" or "below" the arts and sciences, difficulties arise and disagreements issue.

Consider two alternatives:

(1) Paradigm of philosophy as a 'metagrammar'. It (reduced to its essence) asserts: The object of philosophic inquiry is the clarification of the meanings of expressions, and their appropriate/inappropriate usage, by means of the ordinary language. Call this the MG para digm.

(2) Paradigm of philosophy as a 'metascience'. It (reduced to its essence) asserts: The object of philosophic inquiry is the clarification of the meanings of concepts and their logical/dialectical interrelations by means of the ideal language. Call this the MS paradigm.

The key terms are (in MG) 'usage' and 'ordinary language'; and (in MS) 'concepts' and 'ideal language'. That defines the difference between them. To adopt MG entails taking the 'linguistic turn'; to adopt MS entails taking the 'conceptual turn'.

The challenge of MG (already familiar) is to insist that, behind nearly all philosophic puzzles, lie grammatical misunderstandings of one kind or another, and that, when these misunderstandings are exposed, the puzzles dissolve. Accordingly MG philosophers are preoccupied with the "snares of language", wherein lies the source of all our philosophic malaise, and wherein all philosophic remedies are to be sought. Thus, e.g., they would say that Kant's 'antinomies of pure 
reason' were generated by grammatical misunderstandings; and that Kant, despite his demonstrably kcen analytical powers, was oblivious to these simplistic errors. But anyone who understands anything about the dialectic of the conceptual problems which Kant handled, and toward the solution of which he contributed, would find such an explanation unplausible, to say the least. Kantian analyses did result in important conceptual distinctions.

MS, accordingly, would challenge MG as follows: (a) that no genuine conceptual problem can be dissolved by changing our ways of talking about them (and to think otherwise is to entertain a 'philosophic illusion'); and (b) that of any philosophic analysis it may be said, either that it results in conceptual elucidation, or that it results in no conceptual elucidation; in the one case it is significant, in the other it is trivial. Therefore, 'conceptual analysis', and not 'linguistic analysis', constitutes the proper function of philosophy.

The contrast between the two paradigms could not be starker.

Yet, the two paradigms are not wholly unrelated. MG (as will be seen) rests upon a mistake. To overcome the mistake, one must take a 'critical step', from language to metalanguage. Then one sees that the elucidation of 'logical form' becomes accessible. Taking this 'critical step' directly leads to the basic assumption of MS. That is the dialectical relation between the two para digms.

The question, then, is: Was the 'linguistic turn' really based upon a mistake?

The mistake underlying the MG paradigm was occasioned by a mistake occurring in the Tractatus. In the context of the Tractatus the mistake was understandable. But in the context of the 'linguistic turn' it acquired an hyperbolic exaggeration.

Consider the pair of propositions in the Tratatus:

$P_{1}$ : "Philosophy aims at the clarification of thoughts" (4.112a). 
and

$\mathrm{P}_{2}$ : "Philosophy does not result in "philosophic propositions" " $(4.112 \mathrm{~d})$.

Logically speaking, $\mathrm{P}_{1}$ does not imply $\mathrm{P}_{2}$; for it is not contradictory to assert $P_{1}$ while negating $P_{2}$. One may argue, on the contrary, that the negation of $P_{2}$ is implied by $P_{1}$, on the condition of introducing the following assumption:

$P_{3}$ : The logical form of thought (language) can be described by a metalanguage.

This is the 'critical step'.

$\mathrm{P}_{3}$ introduces the language/metalanguage distinction; and thereby rejects the thesis that the 'logical form' of thought can be shown but not described.

From the conjuntion of $P_{1}$ and $P_{3}$ we obtain:

$\mathrm{P}_{4}$ : Philosophy results in 'philosophic propositions'.

And from the conjunction of $\mathrm{P}_{3}$ and $\mathrm{P}_{4}$ we obtain:

$\mathbf{P}_{5}$ : Philosophic propositions describe the 'logical form' of thoughts.

The assumption of $P_{3}$ (our 'critical step') is now a commonplace. Wittgenstein (as everyone knows) did not hold this assumption; but (as not everyone knows) he could not hold this assumption. The explanation, in retrospect, is clear: Wittgenstein, the builder of the picture theory of language, did not envision the possibility of a metalanguage. Hence, in the context of his logical atomism, all propositions were of equal value (gleichwertig). But, we know, he actually used what he did not formally admit. Thus, firstly, he posited a 'logical space'; and, secondly, he made a working distinction, to say the least, between the 'senseless' (sinnlos) and the 'nonsensical' (unsinning). So he was able to make room for 
logico-philosophic propositions within his system. Yet, in the end, he refused to assign these propositions any denotative function. That was his mistake. This inconsistency between Wittgenstein's theory and his practice of philosophy persisted - until it ended in the inevitable repudiation of Wittgenstein I by Mittgenstein II. For (we must agree with Bergmann) the Untersuchungen was only "the reaction, dictated by the counsel of despair, to the failure" of the Tractatus.

From the mistake of the master to the mistake to be made by his epigones was but a single step: Since $(a)$ 'philosophic propositions' lacked a denotative function, $(b)$ they could not say anything about the world, and therefore $(c)$ they were vacuous. That is the implicit argument behind the $M G$ paradigm. Its conclusion (c) follows from its premises; but the premise $(a)$ is questionable. If one accepts $\mathrm{P}_{5}$, then one must reject (a). But one cannot accept $\mathrm{P}_{5}$ without taking the 'critical step' $\left(\mathrm{P}_{3}\right)$, i.e., without assuming the language/ metalanguage distinction. The MG philosophers, failing to take the language/metalanguage distinction seriously, failed to take the 'critical step'. That was their mistake. They consequently never arrived at $\mathrm{P}_{5}$. They did not see that 'philosophic propositions' may say something about the logical form of thought and, consequently, the logical form of the world (insofar as the latter is intelligible within our conceptual schemata). So they remained mired in arbitrary grammarizing about the appropriate/inappropriate usage of expressions in ordinary language.

The consequence of the mistake was a paradox (already evident in the last pages of the Tractatus and, subsequently, in the discourses of the Oxford philosophers): That the philosophic propositions asserted by these philosophers, including propositions concerning the meaning of 'philosophic propositions', were themselves meaningless if true, and meaningful only if false. Wittgenstein himself saw the point: "My propositions serve as elucidations in the following way: Anyone who understands me eventually recognizes them as nonsensical [sic], when he has used them - as steps- to climb up beyond them." (6.54) But his advice to the readers of the Tractatus, 
i.e. to throw the ladder away after having climbed up on it, could hardly apply to the readers of the Untersuchungen (i.e. the MG philosophers at Oxford and elsewhere), who remained without any "logical scaffding" and certainly without a "ladder".

The MS paradigm accepts $P_{5}$. It can answer the dilemma -philosophy must be either science or nothing- therefore: Philosophy is, neither science nor nothing, but a 'metascience'.

II. Toward a Redefinition of 'Philosophy' and

'Philosophic Propositions'

\section{Definition}

Philosophy is the metascience of invariant concepts and basic paradigms. Its method of inquiry consists of the elucidation of concepts and the logical/dialectical construction of paradigms.

Its results are:

(a) philosophic propositions concerning the meanings of concepts and their logical/dialectical interrelations;

b) philosophic paradigms concerning general patterns which interrelate aspects of art, science, and life.

\section{Explication}

'Metascience' means: Inquiry into the realm of basic concepts and problems which are presupposed and/or implied by the special arts and sciences, but which lie beyond the range of their limited methodologies. Only the logical/dialectical methodology of 'modern philosophy' can handle these metascientific concepts and problems. 'Metascience' (not 'metaphysics"!) is ontologically neural: It is not handicapped by dualistic prejudices or anti-scicntific tendencies.

'Invariant concepts' are those basic concepts which recur in the discourses of the various arts and sciences, and whose meanings are presupposed throughout these diverse contexts. Examples of 'invariant concepts' are: 'truth', 'meaning', 
'value', 'causality', 'form', 'system', 'actuality', 'potentiality', 'possibility', 'harmony', a.o. These invariant concepts (and their constancies of meanings) constitute the exclusive objects of philosophic inquiry.

'Philosophic paradigms' depict relations between systems of relations. They are constructed logically/dialectically out of the analogies of experience and/or reflection. Examples of 'philosophic paradigms' are: epistemic models, cosmic models, and ethical models.

\section{Philosophic propositions}

The special character of philosophic propositions, which distinguishes them from every form of nonphilosophic propositions, consists in this: That they depict the logical form of concepts and/or relations between concepts.

Thus 'philosophic propositions' are, neither factual statements (i.e. propositions about particular events in the world), nor linguistic statements (i.e. propositions about the appropriate/inappropriate usage of expressions in ordinary language), but rather logical statements.

Philosophic propositions elucidate the logical form of thought (about the world): Therefore they provide a priori knowledge.

A priori propositions derive their truth, directly or indirectly, from the meanings of their concepts in the context of the 'ideal language'.

There are two kinds of a priori propositions:

(AA) analytic a priori propositions which involve concepts representing the contents of knowledge; e.g. 'At least two points lie on any given line';

(SA) synthetic a priori propositions which involve concepts representing the conditions of knowledge; e.g. 'Every phenomenon has a cause.'

The difference between these two kinds of propositions lies in that they occur at different epistemic levels. $A A$ 
occurs at the level of the conditioned, while $S A$ occurs at the level of the precondition: $A A$ describes the structure of concepts; $S A$, the logical conditions for the intelligibility of our knowledge about any structure whatever. Hence the derivation of $A A$ is relatively direct, while that of $S A$ is rather indirect (as it involves transcendental deduction). Thus, e.g., the causal principle (stated above) is to be derived, not directly from the meanings of its concepts, but indirectly, by their reduction to the ground-concepts of 'being' and 'becoming', and only then it becomes analytically evident that the assertion of the proposition 'Being becomes from nonbeing' (which entails the negation of the causality principle) is self-contradictory. Thus, while $A A$ usually results in definitions, $S A$ results in reductions. Both kinds of propositions add to our knowledge of the form of the intelligible world'. Our main assumption here being, that the world of logical forms is a 'possible world', an assumption which will be exposed in the last section of this article.

III. Relations of Philosophy to the Arts and Sciences

Philosophy is the scaffolding of the arts and sciences. That is the main thesis. Its meaning may be elucidated by focussing on the twofold relations which hold between philosophy and the arts and sciences:

(1) Philosophy articulates the epistemological presuppositions (i.e. invariant concepts and assumptions) of the arts and sciences.

(2) Philosophy reconstructs the cosmological implications (i.e. philosophic paradigms) of the arts and sciences.

Thus philosophy examines, at two different levels, the relations betwcen systems of relations. 
III. 'Modern Philosophy': General Order

II. Arts \& Sciences: Special Orders

I. Reality: Unknown Order

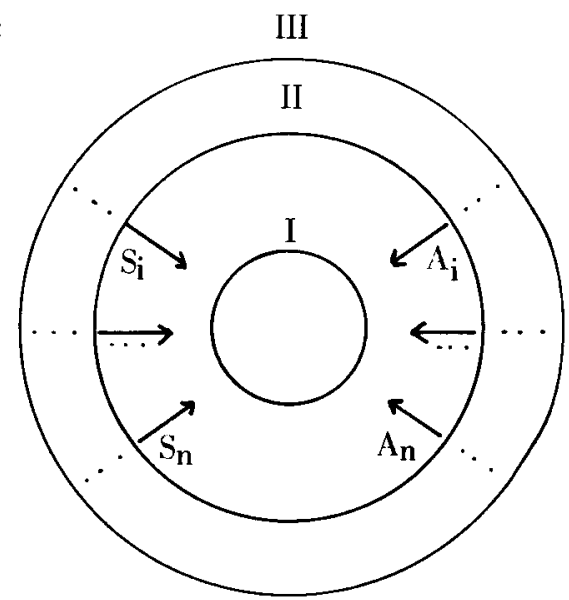

(Paradigm of Three Concentric Circles)

Three concentric circles depict the relation of philosophy to the arts and sciences and to reality. As the picturing of reality by the arts and sciences progresses, the innermost circle approaches the midcircle. But the midcircle, regardless of the extent of its expansion, will never coincide with the outer circle. Metascientific problems remain beyond the reach of scientific methodology. Only the logical/dialectical methodology of 'modern philosophy' can handle these problems. Thus the roles of the arts and sciences and the role of philosophy, vis-à-vis reality, are complementary.

IV. Ontological Assumptions of the 'Conceptual Turn'

Professor Bergmann once remarked: "The 'latent content' of many recent and current discussions is ontological; their 'manifest content' is something else." I agree. Let us, therefore, lay out the "latent content" of the "conceptual turn' alongside its "manifest content". But let there be no misunderstanding: 
Fxhibiting one's assumptions is not demonstrating them. The latter would be a task for another essay.

The ontological assumptions of the 'conceptual turn' are clustered around one word: 'Realism'.

Specifically: One must assume, in taking the 'conceptual turn', the reality of 'logical space' and the possibility of the construction/reconstruction of concepts and propositions therein. This is the philosophic core of 'realism'; its circumference is another matter. Phenomenology operates on the circumference of reality.

I use the word 'realism', philosophically, in three senses:

Realism $_{1} \quad$ states that 'mental acts' exist, or, have ontological status.

Realism $_{2}$ states that the 'external world' exists independently of our awareness of it.

Realism $_{3}$ assigns denotative function to the symbolic expressions of scientific/philosophic language.

The logical issue underlying these senses of 'realism' concerns the meaning of the expression 'exists'.

I define:

To 'exist' is to be the referent of a symbol in the ideal language.

Symbolically:

$$
E(x)=d f \quad(\exists a)[(a: x) \wedge(a \in L)]
$$

Such a definition of 'existence' avoids the usual circularity. It retains the distinction between the 'existential predicate' $(E)$ and the 'existential quantifier' $(\exists)$. The former refers to 'existence', as a higher level concept; and the latter to 'existents', as a lower level concept. Or (to use a Kantian expression) one says that 'existence' is not a predicate of 
objects. The question, what is 'existence' (isness), is a philosophical issue; but the question, what are 'existents' (or kinds of existents), is a scientific issue. (This demonstrates, incidentally, that the Quinean question, concerning "what there is", in terms of which he defines the task of ontology, is either ambiguous or, if clear, a very nonphilosophical question.)

Being a realist in the sense of Realism 1 does not entail being a realist in the sense of Realism ${ }_{2}$, and conversely. But being a realist in the sense of either Realism 1 or Realism

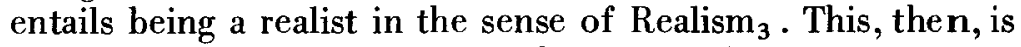
the common bond between these two forms of realism against nominalism. Some are realists of one kind (blending Realism $_{1}$ and Realism $_{3}$ ) or of another (blending Realism 2 and Realism $\left.{ }_{3}\right)$. They are, strictly speaking, quasi-realists. Others (those, including this writer, who have taken the 'conceptual turn') are complex-realists. They are realists in all three senses of the term. One can hardly take the 'conceptual turn', without embracing, eventually, a complex ontological realism.

The ontological assumptions of the 'conceptual turn' (as I reconstruct it) may be illustrated by the following schema:

Mind

(Mental Acts)

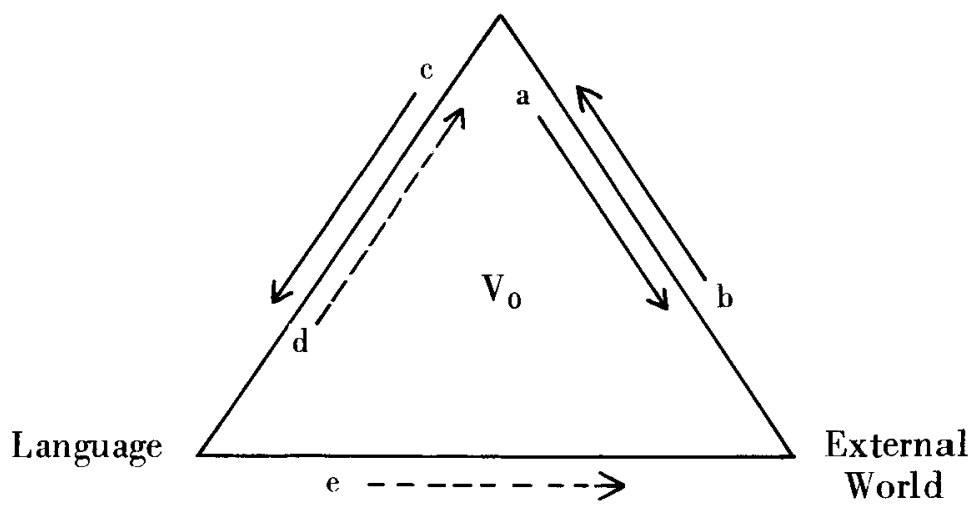


Let this 'Epistemological Triangle' $\left(\mathrm{V}_{0}\right)$ serve as a model for a complex/critical realism - where :

$a=$ categorial matrix of possible experience

$\mathrm{b}=$ empirical contents of actual experience

$c=$ symbolic expression of concepts/propositions

$\mathrm{d}=$ mental denotata $\}$ *

$\mathrm{e}=$ material denotata $\}$

* 'picture theory' of language (of the kind contributed by Wittgenstein) is assumed.

Compare three quasi-realistic variations of the 'Epistemological Triangle': (The letters W, M, and L stand for World, Mind, and Language, respectively)
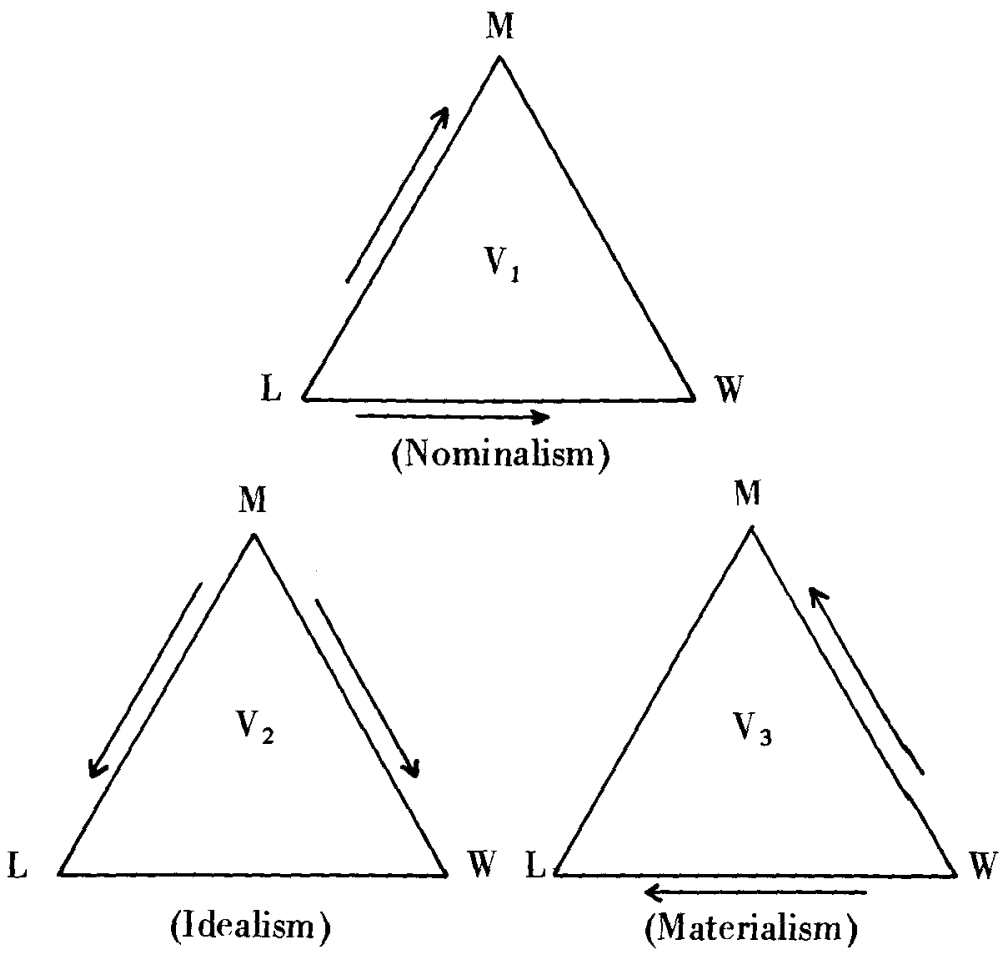
Symbolically:

$\begin{array}{lll}\forall x\left(x \in V_{1}\right) & \forall x\left(x \in V_{2}\right) & \forall x\left(x \in V_{3}\right) \\ \equiv(x \in L v L \rightarrow x) & \equiv(x \in M v M \rightarrow x) & \equiv(x \in W v W \rightarrow x)\end{array}$

Three eclipsed worlds $-V_{1}, V_{2}, V_{3}$ - representing nevertheless three 'possible worlds'. Skepticism rejects them each on dialectical grounds alone. Critical realism overcomes them by radically reconstructing them - as shown by $V_{0}$ aboveand the validity of the reconstruction is to be determined by its range of explanation.

\section{A Note on the Methodology of the 'Conceptual Turn'}

The methodological requirements of the 'conceptual turn' -i.e., that there are levels of analysis (ranging from the 'exhibition analysis' at the surface level, to the 'replacement analysis' at the mediate level, to the 'reductive analysis' at the basic level); or that analysis (as the elucidation of concepts) and synthesis (as the construction of paradigms) are complementary operations; or that the ideal language (namely, the technical language with a capacity for logical precision and ontological neutrality), rather than "ordinary language", is the proper language of philosophic inquiry - these methodological issues will be handled by this writer in another article.

\section{A SAMPLE BIBLIOGRAPHY OF THE 'CONCEPTUAL TURN'}

The materia philosophica representing the 'conceptual turn' are sufficiently extensive to fill an entire issue of this journal. They fall roughly into two groupings: Those works which treat of ground-issues, and those which examine special problems in philosophy, both representing (explicitly or implicitly) the conceptual approach to issues. My list is illustrative rather than exhaustive.

A gassi, J., 'Criteria for Plausible Arguments", Mind, 1974, v. 83, no. 331.

Bealer, G., Quality and Concept, Oxford: Clarendon Press, 1982.

Bergmann, G., "Remarks on Realism", Philosophy of Science, 1946, v. 13: and "Realistic Postscript", in Logic and Reality, Madison: University of Wisconsin Press, 1964. 
, "The Glory and the Misery of Ludwig Wittgenstein", in Logic and Reality, Madison: University of Wisconsin Press, 1964. (Originally published in Rivista di Filosofia, 1961, v. 52.)

Bunge, M., "Is Scientific Metaphysics Possible?", in Method, Model, and Matter, Dordrecht/Boston: Reidel Co., 1973. "The GST Challenge to the Classical Philosophies of Science", International Journal of General Systems, 1977, v. 4.

, Treatise on Basic Philosophy: I.IV, Dordrecht/Boston: Reidel Co., 1974-1983.

Chisholm, R.M., Theory of Knowledge, Englewood: Prentice-Hall Inc., 1966/ 1977; cf. H. Heidelberger, "Professor Chisholm's Epistemic Principles", Noũs, 1969 , v. 3.

Gauthier, Y., Théorétiques: Pour une philosophie constructiviste des sciences, Montréal: Le P réambule Inc., 1982.

Gobar, A., "A bstract Entities in the Natural Sciences", Akten des XIV Internationalen Kongresses für Philosophie, Vienna, 1968, Bd. I. 1982 , v. 4 , no. 1 . "A Critique of Current Theories of Truth", Philosophical Inquiry, "Are There Types of Truth?", Dialectica, forthcoming.

Gonseth, F., "Les mathématiques et la réalité", Dialectica, 1975, v. 29, no. 1 . Gram, M.S., Kant, Ontology, and the A Priori, Evanston: NWU Press, 1968.

\& Klemke, E.D. (eds.), The Ontological Turn: Studies in the Philosophy of G ustav Bergmann, Iowa City: University of Iowa Press, 1974.

Grossmann, R., Ontological Reduction, Bloomington: Indiana University Press, 1973.

Hartmann, K., "On Taking the Transcendental Turn", Review of Metaphysics, 1966, v. 20 , no. 2.

- "Analytic versus Categorial Thought", in Contemporary A spects of Philosophy (cd. Gilbert Ryle), London: Oriel Press, 1976.

Hintikka, J., Models for Modalities, Dordrecht/Boston: Reidel Co., 1969.

"Possible-Worlds Semantics as a Framework for Comparative and Critical Philosophy", in Contempomry Aspects of Philosophy (ed. Gilbert R yle), London: Oriel Press, 1976.

Körner, S., "Description, Analysis, and Metaphysics", in The Nature of Philosophical Inquiry (ed. J. Bobik), Notre Dame: University of Notre Dame Press, 1970.

, Categorial f'rameworks, Oxford: Blackwell Co., 1970

Kokoszyńska, Maria, 'Definitionen im engeren und weiteren Sinne', Deutsche Zeitschrift für Philosophie, 1976, Bd. 24.

Kreisel, G., 'Wittgenstein's Theory and Practice of Philosophy', British Journal for the Philosophy of Science, 1960, v. 11.

Laszlo, E., Introduction to Systems Philosophy, New York/London/Paris: G\&B Publishers, 1972.

Linke, P. F., Niedergangserscheinungen in der Philosophie der Gegenwart, München/ Basel: Reinhardt Vg., 1961.

Markoviĉ, M., Dijalekticka Teorija Znacenja [Dialectical Theory of Meaning], Belgrade, 1961.

- "The Problem of Truth", in Boston Studies in the Philosophy of Science, Dordrecht/Boston: Reidel Co., 1969, v. 5.

Montague, R., "Universal Grammar", Theoria, 1970, v. 36. 
Mundle, C.W.K., A Critique of Linguistic Philosophy, Oxford: Clarendon Press, 1970.

Rescher, N., "Recent Developments in Philosophical Logic", in Contemporary Philosophy (ed. R. Klibansky / ICP), Firenze: Nuova Italia Editrice, 1963, v. I.

Saarinen, E. (ed.), Conceptual Issues in Ecology, Dordrecht/Boston: Reidel Co., 1982.

Stegmüller, Wg., Wissenschaftliche Erklärung und Begründung, Berlin/ Heidelberg: Springer Vg., 1969.

Verlag, 1979.

Neue Wege der Wissenschaftsphilosophie, Berlin/Heidelberg: Springer

, The Structuralist View of Theories, Berlin/Heidelberg/New York: Springer Vg., 1979.

Stenius, E., Wittgenstein's Tractatus: A Critical Exposition of its Main Lines of Thought, Oxford: Clarendon Press, 1960.

Cf. Commentary by G. Bergmann in Theoria, 1963, v. 29.

"'The Concepts 'Analytic' and 'Synthetic',", in Contemporary Philo-

sophy in Scandinavia (eds. R. Olson \& A. Paul), Baltimore: Johns Hopkins Press, 1972.

, Critical Essays, Amsterdam: North Holland Publishing Co., 1972.

Stigen, A., "The Concept of Mind" [A Critique of Ryle's Theory], in Danish Yearbook of Philosophy, Copenhagen, 1965, v. II.

"Two Kinds of Expressions: Makings-Known and Manifestations", Akten des XIV Internationalen Kongresses für Philosophie, Viena, 1968, Bd. I. _- "Philosophy as Worldview and Philosophy as Discipline", in Contem. porary Philosophy in Scandinavia (eds. R. Olson \& A. Paul), Baltimore: Johns Hopkins Press, 1972.

Tömebohm, H., A Logical Analysis of the Theory of Relativity, Stockholm: A lmqvist \& Wiksell, 1952, especially Part II.

V on Wright, G. H., Philosophical Logic, Ithaca: Cornell University Press, 1983. ,Practical Reason, Ithaca: Cornell University Press, 1983.

, The Varieties of Coodness, London: Routledge \& Co., 1963.

Vuillemin, J., 'Logical Flaws or Philosophical Problems: On Russell's Principia Mathematica", Revue Internationale de Philosophie, 1972, v. 26, no. 102.

, La logique et le monde sensible, Paris: Flammarion \& Cie., 1971.

Wein, H., "Über die Grenzen der Sprachphilosophie", Zeitschrift für philosophische Forschung, 1961, v. 15, no. 1.

Weissman, D., Eternal Possibilities: A Neutral Cround for Meaning and Existence, Carbondale: S.I.U. Press, 1977.

Williams, C.J.F., What is Existence?, Oxford: Clarendon Press, 1981.

Weingartner, P. (hg.), Deskription, Analytizität, Existenz, Salzburg/München: Verlag A.P., 1966. 
RESUMEN

Tanto el significado como la razón de ser del "cambio conceptual", evento de reconocida importancia en la filosofía contemporánea, se explican en términos de: (a) el surgimiento de la concepción de la filosofía como una "metaciencia" (versus una "metagramática"); (b) la reconstrucción del argumento que cstá en la base de este "cambio conceptual"; y, finalmente, (c) los presupuestos ontológicos (mostrados por el modelo del "triángulo epistemológico") necesarios para el cambio. El dilema común en muchos círculos filosóficos de que o bien la filosofía es una ciencia o no es nada, es superado así: la filosofía es la metaciencia de los conceptos y los paradigmas invariantes. Y es sobre esta base que es posible redefinir, $a b$ novo, la relación complementaria entre la filosofía moderna y las artes y las ciencias.

[A.G.; Trad. Raymundo Morado] 